\title{
A comparative study on corrosion kinetic parameter estimation methods for the early stage corrosion of Q345B steel in 3.5wt\% $\mathrm{NaCl}$ solution
}

\author{
Shuang-yu Cai, Lei Wen, and Ying Jin \\ National Center for Materials Service Safety, University of Science and Technology Beijing, Beijing 100083, China \\ (Received: 18 January 2017; revised: 22 April 2017; accepted: 3 May 2017)
}

\begin{abstract}
Corrosion kinetic parameters play an important role in researchers' ability to understand and predict corrosion behavior. The corrosion kinetic parameters of structural steel Q345B specimens immersed in 3.5 $\mathrm{wt} \% \mathrm{NaCl}$ solution for $1-2 \mathrm{~h}$ were determined using linear polarization resistance (LPR), Tafel-curve multiparameter fitting, electrochemical impedance spectroscopy (EIS), and electrochemical frequency modulation (EFM) methods. The advantages and disadvantages of each method were investigated and discussed through comparative investigation. Meanwhile, the average corrosion rate was examined using traditional coupon tests. The results showed that the corrosion current density values estimated by EFM at a base frequency of $0.001 \mathrm{~Hz}$ and those obtained by Tafel-curve four-parameter fitting (TC4) are similar and consistent with the results of coupon tests. Because of their slight perturbation of the corrosion system, EIS and EFM/TC4 in collaborative application are the recommended techniques for determining the kinetics and the corresponding parameters for the homogeneous corrosion of the naked metal. In our study of the electrochemical kinetics, we obtained much more abundant and accurate electrochemical kinetic parameters through the combined use of different electrochemical methods.
\end{abstract}

Keywords: structural steel; corrosion kinetics; Tafel curve; electrochemical impedance spectroscopy

\section{Introduction}

Metal corrosion is primarily an electrochemical process involving metal oxidation and simultaneous reduction of some other species [1], where corrosion current is one of the most important kinetic parameters. Corrosion current has therefore long been considered an important research subject for corrosion researchers. A number of techniques have been developed and widely applied in various fields, including nuclear power systems [2-4], the petrochemical industry [5-9], aviation and space flight [10], and the construction of reinforced concrete structures [11-15]. These techniques can be classified into two types: non-electrochemical and electrochemical measurements.

The most commonly used non-electrochemical techniques are the coupon test measurement, the electrical resistance (ER) method [16-17], and visual inspection. As a traditional technique, the coupon test method is considered the "gold standard" of corrosion testing and is certainly the simplest way to evaluate metallic corrosion. However, it is time-consuming, cannot be used to obtain real-time data, has limited sensitivity, and can only provide a proper prediction of corrosion rate for homogeneous corrosion. Corrosion monitoring probes based on tracing the changes in ER have been in use since the $1950 \mathrm{~s}$ [18-19]. ER probes are often selected for field applications because of their relatively simple operating principle, few maintenance requirements, ease of data interpretation, and ability to acquire data in real-time [20]. However, the formation of electrically conductive corrosion products/surface deposits or the occurrence of localized corrosion on the sensing component can result in erroneous detection [21].

Many electrochemical techniques for estimating corrosion kinetic parameters have been developed, including linear polarization resistance (LPR) [22-25], potentiodynamic polarization [5-6,26-28], electrochemical noise (ECN) [2,4,29], electrochemical impedance spectroscopy (EIS) [30-33], and harmonic distortion analysis [34-36]. However, each of these electrochemical techniques has advantages and disadvantages. For instance, LPR can be used to obtain the pola-

\footnotetext{
Corresponding author: Ying Jin_E-mail: yjin@ustb.edu.cn

(C) The Author(s) 2017. This article is published with open access at link.springer.com
} 
rization resistance quickly through small-range polarization; however, it cannot be used to calculate the corrosion rate directly unless the Tafel constants are known [37]. The Tafel-curve method is an important technique for determining the corrosion rate in a laboratory setting. Interpretation of the Tafel curve can provide abundant electrochemical parameters; however, the large disturbance potential used in the measurements can damage the specimen surface [1,37]. The literature contains extensive research on the application of specific techniques in certain fields, whereas few investigations have been focused on systematically comparing these techniques.

Q345B, a structural steel, is widely used in ships, bridges, and other ocean engineering fields. Because of the harsh corrosiveness of the ocean environment, marine steel structures have long suffered from serious corrosion. Accordingly, the Q345B/3.5wt\% $\mathrm{NaCl}$ solution corrosion system was investigated in the present work. Several approaches, including LPR, EIS, the Tafel-curve multiparameter fitting method, electrochemical frequency modulation (EFM), and coupon tests, were used to evaluate the corrosion kinetic parameters for a comparative investigation.

\section{Experimental}

\subsection{Materials and equipment}

Table 1 presents the chemical composition of the Q345B used in the experiments. Immersion tests were performed on Q345B coupons $(50 \mathrm{~mm} \times 25 \mathrm{~mm} \times 3 \mathrm{~mm})$ with a $\phi 3-\mathrm{mm}$ hole in their top middle. The specimens for mass-loss measurements were polished to 2000 grit, cleaned ultrasonically in acetone, rinsed with deionized water, and dried under cool flowing air. Polished specimens were used for morphology observations before and after immersion to achieve a better comparison. For electrochemical experiments, the Q345B specimens were mounted in epoxy resin, leaving an exposed area of $10 \mathrm{~mm} \times 10 \mathrm{~mm}$, and subsequently wet-polished with silicon carbide paper to 2000 grit.

Table 1. Chemical composition of the Q345B steel used in the experiments

$\mathrm{wt} \%$

\begin{tabular}{cccccc}
\hline $\mathrm{C}$ & $\mathrm{Mn}$ & $\mathrm{Si}$ & $\mathrm{P}$ & $\mathrm{S}$ & $\mathrm{Fe}$ \\
\hline 0.171 & 0.857 & 0.175 & 0.14 & 0.012 & Balance \\
\hline
\end{tabular}

All experiments were performed at room temperature $\left(20-22^{\circ} \mathrm{C}\right)$ in $3.5 \mathrm{wt} \% \mathrm{NaCl}$ solution under natural aeration conditions. The $\mathrm{NaCl}$ used to prepare the solutions was an analytically pure reagent purchased from Sinopharm Chemical Reagent Co., Ltd., China.

A Gamry Reference 600 potentiostat/galvanostat was used to carry out the electrochemical tests. A saturated calomel electrode was used as the reference electrode, and a $30 \mathrm{~mm} \times 30 \mathrm{~mm}$ platinum plate was used as the counter electrode. The morphologies of the coupons before and after immersion in the test solution were observed using a ZEISS Auriga scanning electron microscope. A Sartorius BSA124S electronic analytical balance with an accuracy of $0.0001 \mathrm{~g}$ was used in the coupon tests.

\subsection{Test methods}

First, the time dependence of the open-circuit potential (OCP) was measured to examine the process by which the corrosion cell became relatively stable in its early stage; the results are shown in Fig. 1. The OCP became stable after approximately $1 \mathrm{~h}$ of immersion. Therefore, prior to all subsequent electrochemical experiments, the specimens were immersed in the test electrolyte for $1 \mathrm{~h}$.

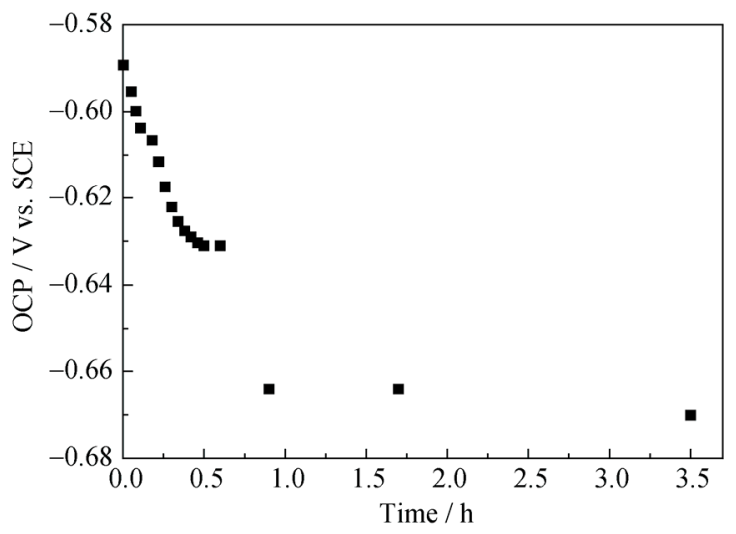

Fig. 1. Time dependence of the open-circuit potential for Q345B immersed in 3.5wt\% $\mathrm{NaCl}$ solution.

\subsubsection{Coupon test method}

Coupon tests were carried out to provide a basis for comparison. Given the similarity between the test conditions and the electrochemical examination conditions and the limited accuracy of coupon tests, we selected three immersion times: 12, 24, and $36 \mathrm{~h}$. All of the specimens were immersed synchronously in a large beaker filled with $2 \mathrm{~L}$ of $3.5 \mathrm{wt} \%$ $\mathrm{NaCl}$ solution under laboratory conditions. During the coupon tests, the ratio between the surface area of each tested specimen and the total volume of solution was $22.6 \mathrm{~mL} \cdot \mathrm{cm}^{-2}$. Three sets of parallel specimens were subjected to coupon tests; the average was calculated and the reproducibility was evaluated.

Prior to mass measurements, the floated rust layer was scraped from the steel surface and the residual rust was removed using a mixed solution composed of $500 \mathrm{~mL}$ hydrochloric acid $+20 \mathrm{~g}$ hexamethylenetetramine $+1 \mathrm{~L}$ deionized water [38]; the specimen was then rinsed with deio- 
nized water and dried under cool flowing air.

\subsubsection{LPR method}

The linear polarization theory was proposed by Stern and Geary in 1957 [39] and was further developed by Mansfeld and Kendig [24-25]. Small polarization near the corrosion potential $E_{\text {corr }}$ is conducted to determinate the corrosion resistance on the basis of the following equation, i.e., the Stern-Geary equation:

$R_{\mathrm{p}}=\frac{\Delta E}{\Delta i}=\frac{b_{\mathrm{a}} b_{\mathrm{c}}}{2.3\left(b_{\mathrm{a}}+b_{\mathrm{c}}\right)} \cdot \frac{1}{i_{\text {corr }}}$

where $R_{\mathrm{p}}$ is the system polarization resistance, $\Delta E$ is the difference between the polarization potential $E$ and the corrosion potential $E_{\text {corr }}$ (i.e., $\Delta E=E-E_{\text {corr }}$ ), $\Delta i$ is the difference between the measured current density $i$ and the corrosion current density $i_{\text {corr }}$ (i.e., $\Delta i=i-i_{\text {corr }}$ ), and $b_{\mathrm{a}}$ and $b_{\mathrm{c}}$ are the anodic and cathodic Tafel coefficients, respectively.

LPR tests were performed in a Q345B/3.5wt $\% \mathrm{NaCl}$ corrosion system from -10 to $+10 \mathrm{mV}$ vs. $E_{\text {corr }}$ with different scan rates ranging from 0.1 to $10 \mathrm{mV} / \mathrm{s}$.

\subsubsection{EIS method}

EIS experiments were carried out using $\pm 5 \mathrm{mV}$ excitation from $10^{5}$ to $10^{-2} \mathrm{~Hz}$ with 5 points per decade. Subsequently, a fitting process based on the simple Randles circuit was used to estimate the value of $R_{\mathrm{p}}$. In addition, single-frequency $(0.01 \mathrm{~Hz}, \pm 5 \mathrm{mV})$ EIS experiments were also performed because the solution resistance was far smaller than the system polarization resistance $R_{\mathrm{p}}$ (i.e., the solution resistance can be ignored).

\subsubsection{Tafel-curve multiparameter fitting method}

Tafel polarizations were carried out in the approximate potential range from -150 to $+150 \mathrm{mV}$ vs. $E_{\text {corr }}$. A scan rate of $1.0 \mathrm{mV} / \mathrm{s}$ was selected to simultaneously shorten the measurement time and minimize the capacitive current.

Exact analysis of a Tafel curve is difficult without knowledge of the step controlling electrochemical process. When metal corrosion is controlled by a charge transfer process, the relationship between the measured current density $i$ and the polarization potential $E$ obeys the Butler-Volmer equation [40]:

$$
i=i_{\text {corr }}\left\{\exp \left[\frac{2.3\left(E-E_{\text {corr }}\right)}{b_{\mathrm{a}}}\right]-\exp \left[\frac{2.3\left(E_{\text {corr }}-E\right)}{b_{\mathrm{c}}}\right]\right\}
$$

Eq. (2) can be simplified in the case of strong anodic/cathodic polarization conditions by neglecting the second/first terms in the right part of the equation, which is well known as the Tafel linear relationship; the simplified equation can then be used to estimate $i_{\text {corr }}$ and the Tafel coefficients [27]. However, if the electrode process is influenced by diffusion in the potential range from -150 to $+150 \mathrm{mV}$ vs.
$E_{\text {corr }}$, the polarization curve equation can be expressed as follows [26-27]:

$$
i=i_{\text {corr }}\left\{\exp \left(\frac{2.3 \Delta E}{b_{\mathrm{a}}}\right)-\frac{\exp \left(-\frac{2.3 \Delta E}{b_{\mathrm{c}}}\right)}{1-\frac{i_{\text {corr }}}{i_{\mathrm{L}}}\left[1-\exp \left(-\frac{2.3 \Delta E}{b_{\mathrm{c}}}\right)\right]}\right\}
$$

where $\Delta E=E-E_{\text {corr }}$, and $i_{\mathrm{L}}$ is the limiting diffusion current density.

Because four kinetic parameters, $b_{\mathrm{a}}, b_{\mathrm{c}}, i_{\text {corr }}$, and $i_{\mathrm{L}}$, are included in Eq. (3), the fitting based on these parameters is referred to as four-parameter fitting [26-27]. When the metal electrode is strongly polarized in the cathodic direction, Eq. (3) can be simplified into the following equation:

$$
i=i_{\text {corr }}\left\{\frac{-\exp \left(-\frac{2.3 \Delta E}{b_{\mathrm{c}}}\right)}{1-\frac{i_{\text {corr }}}{i_{\mathrm{L}}}\left[1-\exp \left(-\frac{2.3 \Delta E}{b_{\mathrm{c}}}\right)\right]}\right\}
$$

or

$$
\Delta E=b_{\mathrm{c}} \lg \frac{i_{\text {corr }}}{i}+b_{\mathrm{c}} \lg \frac{i_{\mathrm{L}}-i}{i_{\mathrm{L}}-i_{\text {corr }}}
$$

Three kinetic parameters, $b_{\mathrm{c}}, i_{\text {corr }}$, and $i_{\mathrm{L}}$, are included in Eq. (5); thus, the fitting process based on this equation is referred to as three-parameter fitting [26].

In the present paper, the relevant corrosion electrochemical parameters were evaluated by linear [27], three-parameter [26], and four-parameter fitting [26-27].

\subsubsection{EFM method}

Corrosion is a nonlinear electrochemical process and thus may produce various response currents under the disturbance of sine-wave signals with different frequencies, such as zero-frequency current, harmonic current, or intermodulation current [41]. The corrosion current density and Tafel constants can be obtained by solving these current equations for different frequencies, which is the principle of the EFM method. Because of the advantages of this method, such as its ability to be carried out without knowledge of the Tafel constants and its slight perturbation of the system ( \pm 5 to 10 $\mathrm{mV}$ ), EFM has become an important online corrosion rate monitoring technique in recent years [41-42].

EFM tests were carried out by setting the base frequency to $1.0,0.1,0.01$, and $0.001 \mathrm{~Hz}$, with four cycles for each frequency, and setting the multipliers to 2 and 5. Compared to the frequency, the amplitude had less effect on the experimental results [43]. In principle, because the deduction of the EFM equation involves a Taylor expansion, the approximate treatment of the EFM equation requires an amplitude as small as possible. In addition, a small amplitude 
also reduces the disturbance of the electrode surface. However, the application of low disturbance signals below \pm 5 $\mathrm{mV}$ renders the measurement of higher harmonic and intermodulation components difficult because of background noise. By comprehensive consideration, we selected $\pm 5 \mathrm{mV}$ as the amplitude of the excitation voltage for the EFM measurements.

\section{Results and discussion}

\subsection{Coupon tests}

Fig. 2 presents the coupon tests results for Q345B steel specimens immersed in $3.5 \mathrm{wt} \% \mathrm{NaCl}$ solution for 12,24 , and $36 \mathrm{~h}$. A comparison of the results for the specimens immersed for different durations reveals that the average corrosion rate tends to decrease slightly after the first $24 \mathrm{~h}$ of immersion; in addition, the fluctuation ranges of the error bars in Fig. 2 increase with increasing immersion time, which is attributed to increasing influence of the corrosion products. For the sake of consistency of immersion time, the coupon corrosion rate corresponding to $12 \mathrm{~h}$ of immersion time, $12.53 \mu \mathrm{A} \cdot \mathrm{cm}^{-2}$, was chosen for the comparative study with other techniques.

To identify the early stage corrosion type of Q345B in $3.5 \mathrm{wt} \% \mathrm{NaCl}$ solution, the tops of the specimens before (blank specimen) and after immersion for $24 \mathrm{~h}$ were observed by scanning electron microscopy (SEM); the corresponding micrographs are shown in Fig. 3. Compared with the surface of the blank specimen shown in Fig. 3(a), the surface of the immersed specimen exhibits many uniformly distributed corrosion pits (Fig. 3(b)), which implies that the early stage corrosion of Q345B in $3.5 \mathrm{wt} \% \mathrm{NaCl}$ solution is homogeneous. Thus, the electrochemical methods applicable to a homogeneous corrosion system were used in subsequent experiments.

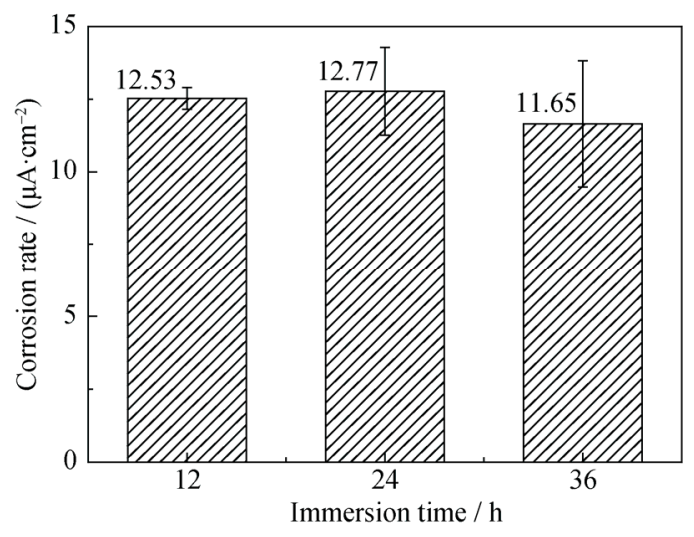

Fig. 2. Corrosion rates calculated from the mass loss of Q345B immersed in 3.5wt\% $\mathrm{NaCl}$ solution for different durations.
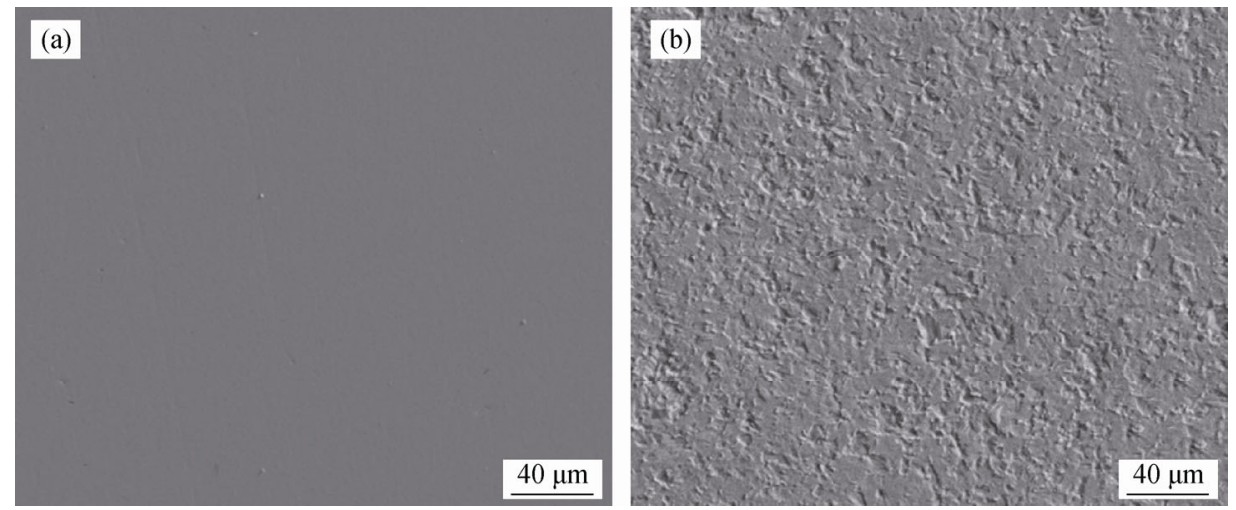

Fig. 3. SEM images of the surface morphology: (a) the blank specimen; (b) the specimen immersed in $3.5 \mathrm{wt} \% \mathrm{NaCl}$ solution for $24 \mathrm{~h}$.

\subsection{LPR tests}

Fig. 4 shows the $R_{\mathrm{p}}$ values obtained via the LPR method using different potential scan rates for Q345B specimens immersed in $3.5 \mathrm{wt} \% \mathrm{NaCl}$ solution. The $R_{\mathrm{p}}$ value increased with increasing scan rate from 0.1 to $0.3 \mathrm{mV} / \mathrm{s}$, fluctuated in a narrow range at scan rates from 0.3 to $1.0 \mathrm{mV} / \mathrm{s}$, and decreased substantially at scan rates from 1.0 to $10 \mathrm{mV} / \mathrm{s}$. The small fluctuation of $R_{\mathrm{p}}$ in the $0.3-1.0 \mathrm{mV} / \mathrm{s}$ range may be attributed to the small OCP variation. The $R_{\mathrm{p}}$ value increased with increasing scan rate from 0.1 to $0.3 \mathrm{mV} / \mathrm{s}$ is similar to the impedance behavior in the low-frequency region of the Bode plot constructed from the EIS data, which will be explained in section 3.3. The dramatic decrease of $R_{\mathrm{p}}$ measured data at potential scan rates larger than $1.0 \mathrm{mV} / \mathrm{s}$ can be explained as follows.

González et al. [44-45] used a modified Randles circuit to simulate the most common electrical-double-layer model of electrochemical corrosion and pointed out by calculation that a suitable scan rate depends on the time required for the polarized system to achieve a steady state, i.e., time constant $\tau$ : 


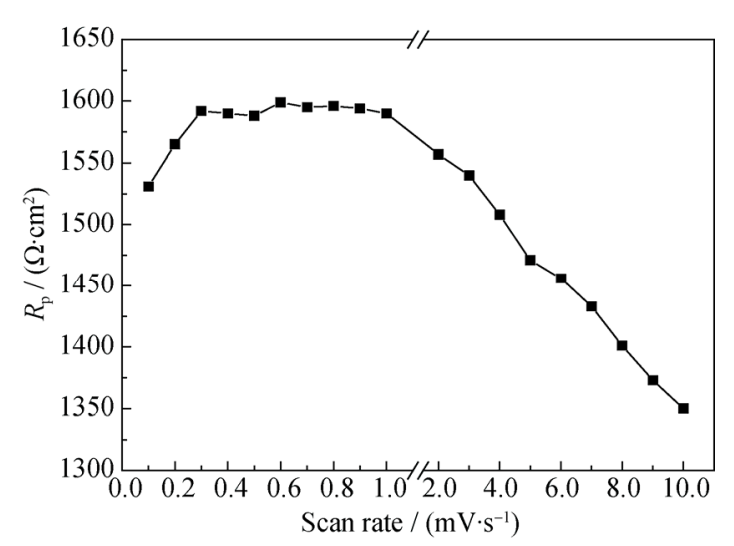

Fig. 4. The $R_{\mathrm{p}}$ values estimated from LPR tests conducted at different potential scan rates.

$$
\tau=\frac{C R_{\mathrm{e}} R_{\mathrm{p}}}{R_{\mathrm{e}}+R_{\mathrm{p}}}
$$

where $R_{\mathrm{e}}$ is the solution resistance and $C$ is the capacitance of the double layer. For an electrolyte system with good conductivity (such as seawater), $R_{\mathrm{p}} \gg R_{\mathrm{e}}$; thus, $\tau \approx C R_{\mathrm{e}}$

A small time constant for a system means that the system can quickly achieve a steady state, which is beneficial for obtaining the stationary $\Delta i$ to calculate $R_{\mathrm{p}}$. As a general rule, after a $\Delta E$ is applied, a waiting time of $5 \leq \tau \leq 6$ is necessary to obtain the stationary $\Delta i$ necessary to calculate $R_{\mathrm{p}}[44]$.

If the scan rate is sufficiently low, the system has sufficient time to achieve a steady state; the transitory component of the response current will then attenuate to be negligible, which ensures good accuracy of $R_{\mathrm{p}}$ values calculated using Eq. (1). Conversely, if the scan rate is very large, the system will fail to achieve a steady state because of the insufficient waiting time; in this case, the transitory component of the response current will not be negligible, making the measured current artificially large and the $R_{\mathrm{p}}$ value calculated using Eq. (1) artificially low.

Therefore, the scan rate obviously affects the $R_{\mathrm{p}}$ measurement (Fig. 4). As some researchers [45] have suggested, a suitable scan rate can be selected on the basis of actual onsite measurement conditions. In the present case, the effect is relatively weaker in the potential scan rate range from 0.3 to $1.0 \mathrm{mV} / \mathrm{s}$. Thus, the mean value of $R_{\mathrm{p}}$ in this range, 1593 $\Omega \cdot \mathrm{cm}^{2}$, was taken as the result of the LPR tests.

\subsection{EIS analyses}

The Nyquist and Bode plots based on the results of the EIS experiments in the frequency range from $10^{5}$ to $10^{-2} \mathrm{~Hz}$ are shown in Figs. 5(a) and 5(b), respectively. In Fig. 5(a), a single deformed inductive loop appears in the low-frequency region, which leads to shrinkage of the real part of the impedance. Using the equivalent circuit shown in Fig. 5(a) to fit the curve while ignoring the last two points in the low-frequency region, we obtained an $R_{\mathrm{p}}$ value of 1639 $\Omega \cdot \mathrm{cm}^{2}$. During the fitting process, a constant phase element was used; its impedance is given by

$Z(\omega)=\frac{1}{Y_{0}(\mathrm{j} \omega)^{n}}$

where $\mathrm{j}=\sqrt{-1}$ and $n$ and $Y_{0}$ are frequency-independent coefficients, and $\omega$ is the angular frequency.

The Bode plot obtained by again neglecting the inflection of the last two points in the low-frequency region (Fig. 5(b)) clearly shows that the corrosion system has only one time constant, which demonstrates the feasibility and effectiveness of the EIS fitting. The EIS results and the corresponding equivalent circuit indicate that, during the $1-2 \mathrm{~h}$ immersion period, the corrosion process of Q345B was controlled by activation rather than by oxygen diffusion, consistent with the results of Melchers and Jeffrey [46].
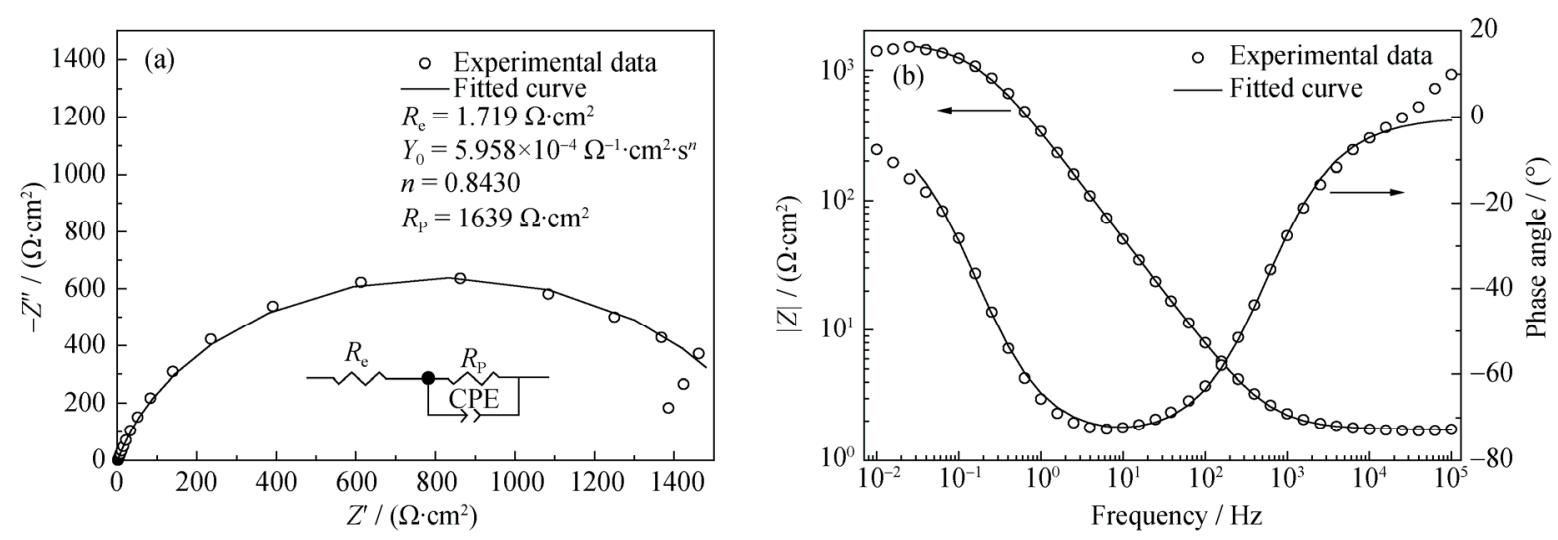

Fig. 5. Experimental EIS data (symbols) and the corresponding fitted data (line) for Q345B immersed in 3.5wt\% NaCl solution: (a) Nyquist plot, where CPE is the constant phase element; (b) Bode plot. 
Fig. 6 presents the results of single-frequency EIS measurements conducted at $0.01 \mathrm{~Hz}$. The impedance values fluctuated near the average value of $1406 \Omega \cdot \mathrm{cm}^{2}$, which is consistent with the real part of the impedance value $(\sim 1400$ $\Omega \cdot \mathrm{cm}^{2}$ ) at $0.01 \mathrm{~Hz}$ shown in Fig. 5(a). The single-frequency EIS results further confirm that the real part of the impedance in Fig. 5(a) shrinks in the low-frequency region.

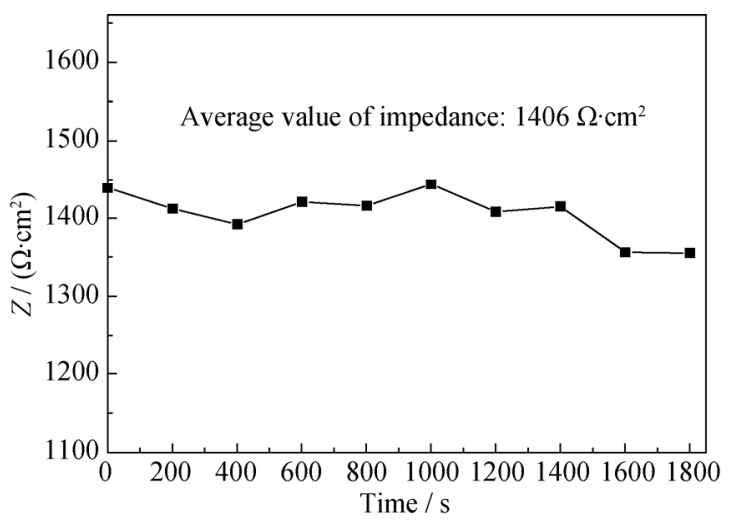

Fig. 6. The $R_{\mathrm{p}}$ values obtained by single-frequency $\left(10^{-2} \mathrm{~Hz}\right)$ EIS for Q345B immersed in 3.5wt\% $\mathrm{NaCl}$ solution.

Generally, the corrosion process of a metal anode can be represented by the general formula:

$\mathrm{M} \rightarrow \mathrm{M}^{n+}+n \mathrm{e}^{-}$

For most commonly used industrial metals, $n>1$. However, in most cases, the $\mathrm{M}$ atom loses an electron first to form a monovalent metal complex and then gradually oxidizes until finally forming stable $n$-valence cation [47]. The reaction intermediates formed during the reaction may be adsorbed onto and/or desorbed from the metal surface.

In the case of a system where electroactive species such as reaction intermediates or corrosion inhibitors adsorb onto the electrode surface, a second impedance semicircle will appear in the complex impedance plane. The actual appearance in the EIS spectrum depends on the time constants of the electrochemical reaction, the values of resistance and capacitance in the equivalent circuit, and the types of adsorptive impedance corresponding to capacitive impedance or inductive impedance [48]. The larger the difference between the time constant $\tau$ of the adsorption process and the time constant $R_{\mathrm{p}} \mathrm{C}_{\mathrm{d}}$ of the electrode reaction, the more the inductive or capacitive loop tends to be a semicircle. Otherwise, as with the phenomenon shown in Fig. 5, when $\tau$ is similar to $R_{\mathrm{p}} \mathrm{C}_{\mathrm{d}}$, the second impedance semicircle corresponding to the adsorption process will partly overlap the first impedance semicircle, forming a single deformed capacitive loop with shrinkage in the real part of the impedance in the low-frequency region.

In the present work, the shrinkage of the real part of the impedance in the low-frequency region shown in Fig. 5(a) and Fig. 6 might be attributable to the time constant $\tau$ of the adsorption process of the reaction intermediates being similar to the time constant $R_{\mathrm{p}} \mathrm{C}_{\mathrm{d}}$ of the electrode reaction during the dissolution reaction of $\mathrm{Fe}$.

\subsection{Tafel polarization}

Fig. 7 shows the Tafel curve of Q345B immersed in $3.5 \mathrm{wt} \% \mathrm{NaCl}$ solution and scanned at a rate of $1.0 \mathrm{mV} / \mathrm{s}$. The anodic polarization is activation controlled, whereas a limiting diffusion plateau clearly exists in the cathodic region. As the OCP drifts toward the negative direction, the natural corrosion process will tend to become oxygen-diffusion controlled, as in the phenomenon reported by Melchers and Jeffrey [46].

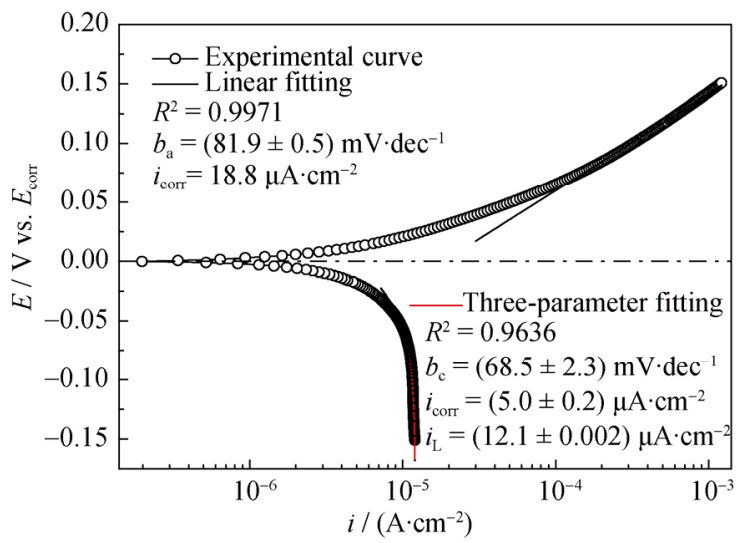

Fig. 7. Polarization curve of Q345B immersed in 3.5wt\% $\mathrm{NaCl}$ solution and scanned at a rate of $1.0 \mathrm{mV} / \mathrm{s}$ from -150 to $+150 \mathrm{mV}$ vs. $E_{\text {corr }}$.

For the anodic process controlled by activation, the corrosion kinetic parameters can be obtained by fitting the Tafel curve in the strong polarization region, i.e., in the region from +70 to $+150 \mathrm{mV}$ vs. $E_{\text {corr }}$, using linear fitting Eq. (10) [27] derived from Eq. (2).

$\Delta E=b_{\mathrm{a}} \lg \frac{i}{i_{\text {corr }}}$

As shown in the anodic region of Fig. 7, a $b_{\mathrm{a}}$ value of 81.9 $\mathrm{mV} \cdot \mathrm{dec}^{-1}$ was determined. By extrapolating the linear fitting line to where $E=0$ vs. $E_{\text {corr }}$, the $i_{\text {corr }}$ value of $18.8 \mu \mathrm{A} \cdot \mathrm{cm}^{-2}$ was roughly determined.

For the cathodic process, because the influence of diffusion mass transfer cannot be neglected, nonlinear three-parameter Eq. (5) was used for fitting the data in the region from -150 to $-30 \mathrm{mV}$ vs. $E_{\text {corr }}$ in Fig. 7. The cathodic region from -30 to $0 \mathrm{mV}$ vs. $E_{\text {corr }}$ was excluded during fitting because of the 
necessity of eliminating the influence of term $\exp \left(\frac{2.3 \Delta E}{b_{\mathrm{a}}}\right)$ in Eq. (3).

Four-parameter fitting of the Tafel curve (TC4) can be used to evaluate more kinetic data; however, proper initial values of the parameters are essential for a successful fitting [26]. In this work, the values of $b_{\mathrm{a}}, b_{\mathrm{c}}, i_{\text {corr }}$, and $i_{\mathrm{L}}$ obtained from Tafel-curve linear fitting and three-parameter fitting were used as the initial values for the four-parameter fitting. Because a large anodic disturbance to the metal might result in erroneous data, the potential range from -150 to $+30 \mathrm{mV}$ vs. $E_{\text {corr }}$ was selected for fitting. As shown in Fig. 8 , anodic and cathodic Tafel constants $b_{\mathrm{a}}, b_{\mathrm{c}}, i_{\text {corr }}$, and $i_{\mathrm{L}}$ were evaluated by four-parameter fitting to be 78.4 $\mathrm{mV} \cdot \mathrm{dec}^{-1}, \quad 103.0 \mathrm{mV} \cdot \mathrm{dec}^{-1}, 12.3 \mu \mathrm{A} \cdot \mathrm{cm}^{-2}$, and 12.3 $\mu \mathrm{A} \cdot \mathrm{cm}^{-2}$, respectively.

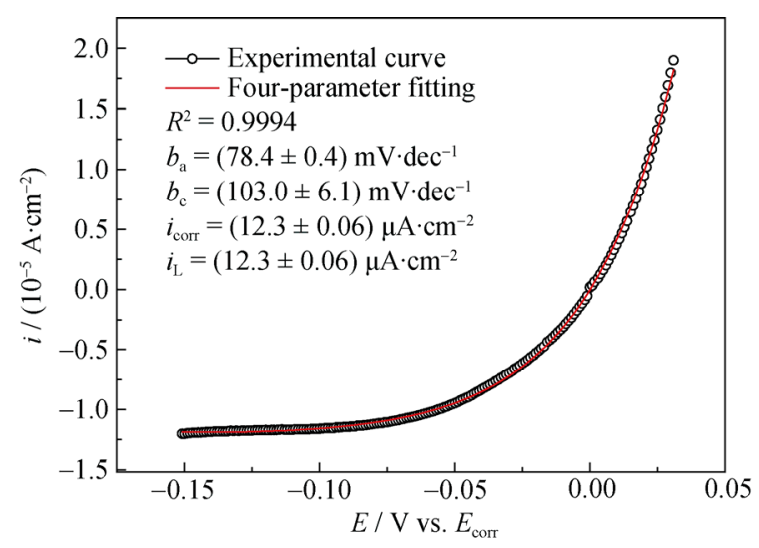

Fig. 8. Four-parameter fitting results for the polarization curve of Q345B immersed in 3.5wt\% $\mathrm{NaCl}$ solution and scanned over the potential range from -150 to $+30 \mathrm{mV}$ vs. $E_{\text {corr }}$.

The cathodic process of the target corrosion system is the oxygen reduction process, which is a complex four-electron reaction:

$\mathrm{O}_{2}+2 \mathrm{H}_{2} \mathrm{O}+4 \mathrm{e}^{-} \rightarrow 4 \mathrm{OH}^{-}$

Because of the generation of unstable intermediates (e.g., $\mathrm{H}_{2}$ $\mathrm{O}_{2} / \mathrm{HO}_{2}^{-}$or adsorbed oxygen/surface oxides [47]), researchers encountered many difficulties in elucidating the process of Eq. (11), resulting in substantially worse understanding of the oxygen reduction process compared to the hydrogen evolution reaction. For most metal electrodes, the oxygen reduction process obeys the mechanism of reactions in Eqs. (12)-(14) [49-51], with the one-electron charge transfer process (Eq. (12)) as the rate-controlling step, irrespective of whether the reaction occurs in acid solution or in alkali solution:

$\mathrm{O}_{2}+\mathrm{e}^{-} \rightarrow \mathrm{O}_{2}^{-}$
$\mathrm{O}_{2}^{-}+\mathrm{H}_{2} \mathrm{O}+\mathrm{e}^{-} \rightarrow \mathrm{HO}_{2}^{-}+\mathrm{OH}^{-}$
$\mathrm{HO}_{2}^{-} \rightarrow \frac{1}{2} \mathrm{O}_{2}+\mathrm{OH}^{-}$

According to the electrochemical equation,

$b_{\mathrm{c}}=\frac{2.303 R T}{\alpha n^{\prime} F}$

where $R$ is the universal gas constant $(8.3147 \mathrm{~J} /(\mathrm{mol} \cdot \mathrm{K})), T$ is the absolute temperature, $\alpha$ is the symmetry factor (generally $\alpha \approx 0.5$ in an ideal state), $n^{\prime}$ is the number of electrons transferred in the rate-controlling step of the reaction, and $F$ is the Faraday's constant (96487 C/equivalent). When $n^{\prime}=1$ and $T=293 \mathrm{~K}$ (room temperature), $b_{\mathrm{c}}$ was determined to be $116 \mathrm{mV} \cdot \mathrm{dec}^{-1}$. A comparison of the $b_{\mathrm{c}}$ values clearly indicates that the $b_{\mathrm{c}}$ value obtained by the four-parameter fitting is much closer to the theoretically calculated value than that calculated by the three-parameter fitting.

For the fitting results presented in Figs. 7 and 8, the $R^{2}$ values, which indicate the goodness of fit, increased from 0.9636 (three-parameter fitting) to 0.9994 (four-parameter fitting), indicating enhanced fitting precision in the case of four-parameter fitting.

\subsection{EFM tests}

Fig. 9 shows the time dependence of current density for Q345B immersed in 3.5 $\mathrm{wt} \% \mathrm{NaCl}$, as detected by the EFM method using several different base frequencies. Obviously, lower EFM base frequencies resulted in longer test durations.

Melchers and Jeffrey [46] proposed that the corrosion of carbon steel immersed in seawater was controlled by activation when the immersion time was less than $5 \mathrm{~d}$. Therefore, for $\mathrm{Q} 345 \mathrm{~B}$ immersed in $3.5 \mathrm{wt} \% \mathrm{NaCl}$ for only a few hours, the corrosion process can be reasonably assumed to be activation controlled, as confirmed by the EIS spectrum and the corresponding equivalent circuit (Fig. 5). The corresponding corrosion kinetic parameters were calculated and are presented in Table 2.

Bosch et al. [41] analyzed the causality factor (CF) to evaluate the quality of EFM. In theory, the CFs follow the following equations:

$$
\begin{aligned}
& \mathrm{CF}(2)=\frac{i_{\omega_{2} \pm \omega_{1}}}{i_{2 \omega_{1}}} \\
& \mathrm{CF}(3)=\frac{i_{2 \omega_{2} \pm \omega_{1}}}{i_{3 \omega_{1}}}
\end{aligned}
$$

where $i_{\omega_{2} \pm \omega_{1}}$ and $i_{2 \omega_{2} \pm \omega_{1}}$ are intermodulation components measured at angular frequencies $\omega_{2} \pm \omega_{1}$ and $2 \omega_{2} \pm \omega_{1}$, respectively, and $i_{2 \omega_{1}}$ and $i_{3 \omega_{1}}$ are those measured at $2 \omega_{1}$ and $3 \omega_{1}$, respectively. 

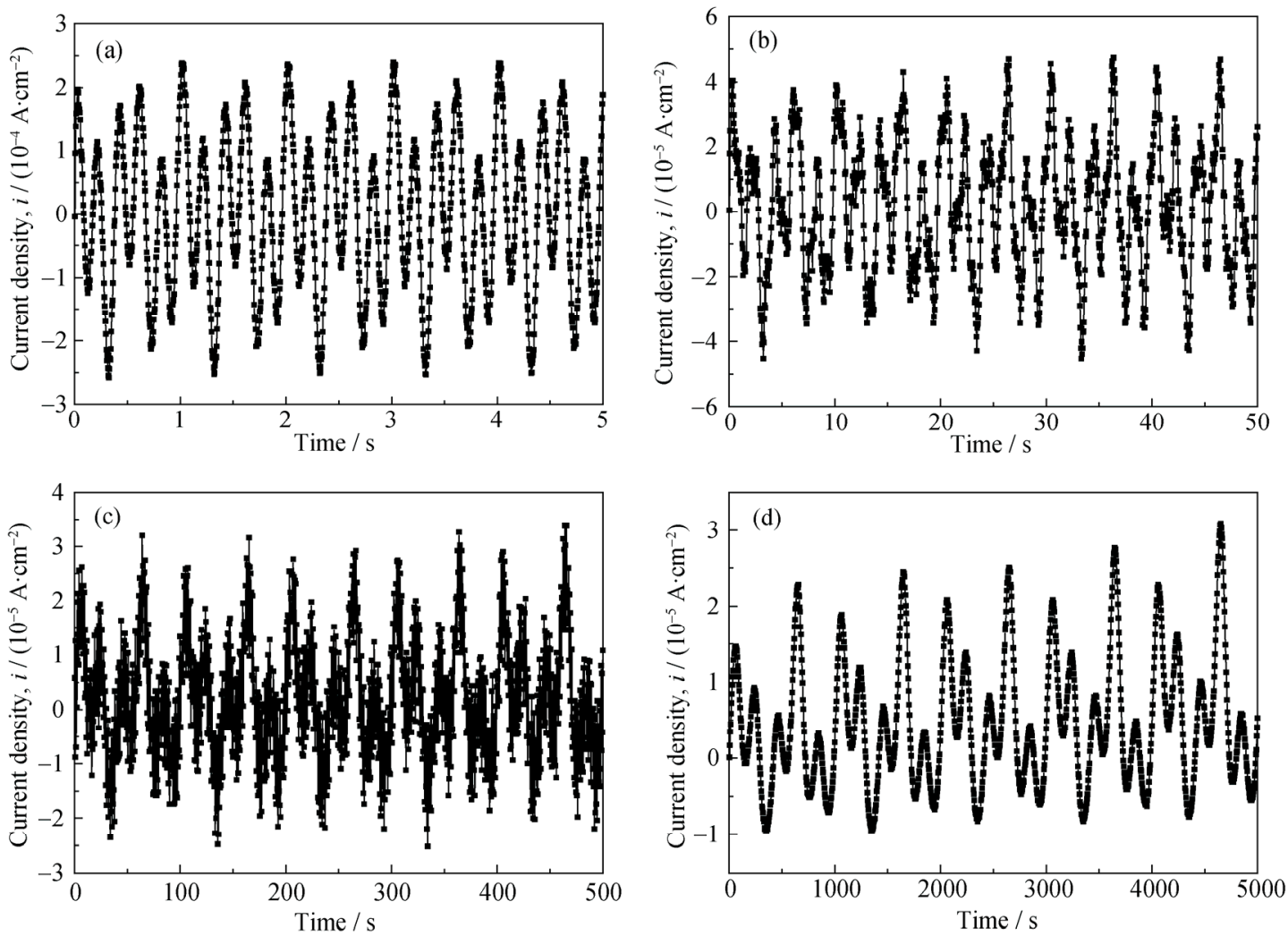

Fig. 9. Corrosion current density of Q345B immersed in 3.5wt\% $\mathrm{NaCl}$ solution, as detected by EFM at different base frequencies: (a) $1.0 \mathrm{~Hz}$; (b) $0.1 \mathrm{~Hz}$; (c) $0.01 \mathrm{~Hz}$; (d) $0.001 \mathrm{~Hz}$.

Table 2. Corrosion kinetic parameters determined by EFM

\begin{tabular}{ccccccc}
\hline Base frequency $/ \mathrm{Hz}$ & $i_{\text {corr }} /\left(\mu \mathrm{A} \cdot \mathrm{cm}^{-2}\right)$ & $b_{\mathrm{a}} /\left(\mathrm{mV} \cdot \mathrm{dec}^{-1}\right)$ & $b_{\mathrm{c}} /\left(\mathrm{mV} \cdot \mathrm{dec}^{-1}\right)$ & $B /\left(\mathrm{mV} \cdot \mathrm{dec}^{-1}\right)$ & $\mathrm{CF}(2)$ & $\mathrm{CF}(3)$ \\
\hline 1 & 368.1 & 162.7 & 255.1 & 43.2 & 1.572 & 0.742 \\
0.1 & 10.4 & 35.1 & 39.6 & 8.1 & 1.890 & 9.403 \\
0.01 & 23.5 & 96.5 & 767.2 & 37.3 & 1.805 & 0.677 \\
0.001 & 12.7 & 64.9 & 195.9 & 21.2 & 1.893 & 1.865 \\
\hline
\end{tabular}

Note: The Stern-Geary value $(B)$ was calculated using the equation $B=\frac{b_{\mathrm{a}} b_{\mathrm{c}}}{2.303\left(b_{\mathrm{a}}+b_{\mathrm{c}}\right)}$ [39].

Values of $\mathrm{CF}(2)$ and $\mathrm{CF}(3)$ that deviate from 2 and 3, respectively, indicate that noise is present in the EFM spectra. As shown in Table 2, compared with the values of $\mathrm{CF}(2)$ and $\mathrm{CF}(3)$ obtained using other base frequencies, those obtained at a base frequency of $0.001 \mathrm{~Hz}$ are closest to 2 and 3 , respectively, implying better reliability of the data obtained at this frequency.

Fig. 10 shows the frequency-domain current response spectra obtained by EFM using different base frequencies. The harmonic current and intermodulation currents shown in Fig. 10(d) are much closer to the ideal situation than those in the other cases, also reflecting the greater reliability of the results obtained at a base frequency of $0.001 \mathrm{~Hz}$. In theory, the frequency of EFM tests should be as low as possible to limit the capacitive current [1]; however, an excessively low frequency will substantially increase the test time, which may restrict the wide application of EFM in the field.

Notably, although both EIS and EFM are nonlinear alternating current (AC) test technologies, their test behaviors differ substantially. First, the disturbance potentials used for EFM and EIS differ from each other (usually, for EFM, $E(t)=U_{0} \sin \left(\omega_{1} t\right)+U_{0} \sin \left(\omega_{2} t\right)$, whereas for EIS, $E(t)=U_{0} \cos (\omega t)$, where $E(t)$ is the excitation signal, $U_{0}$ is the amplitude of the excitation voltage, $\omega$ is the angular frequency, and $t$ is the time), which leads to different current responses. For example, the current response of EFM contains the intermodulation components, whereas the current response of EIS does not. 

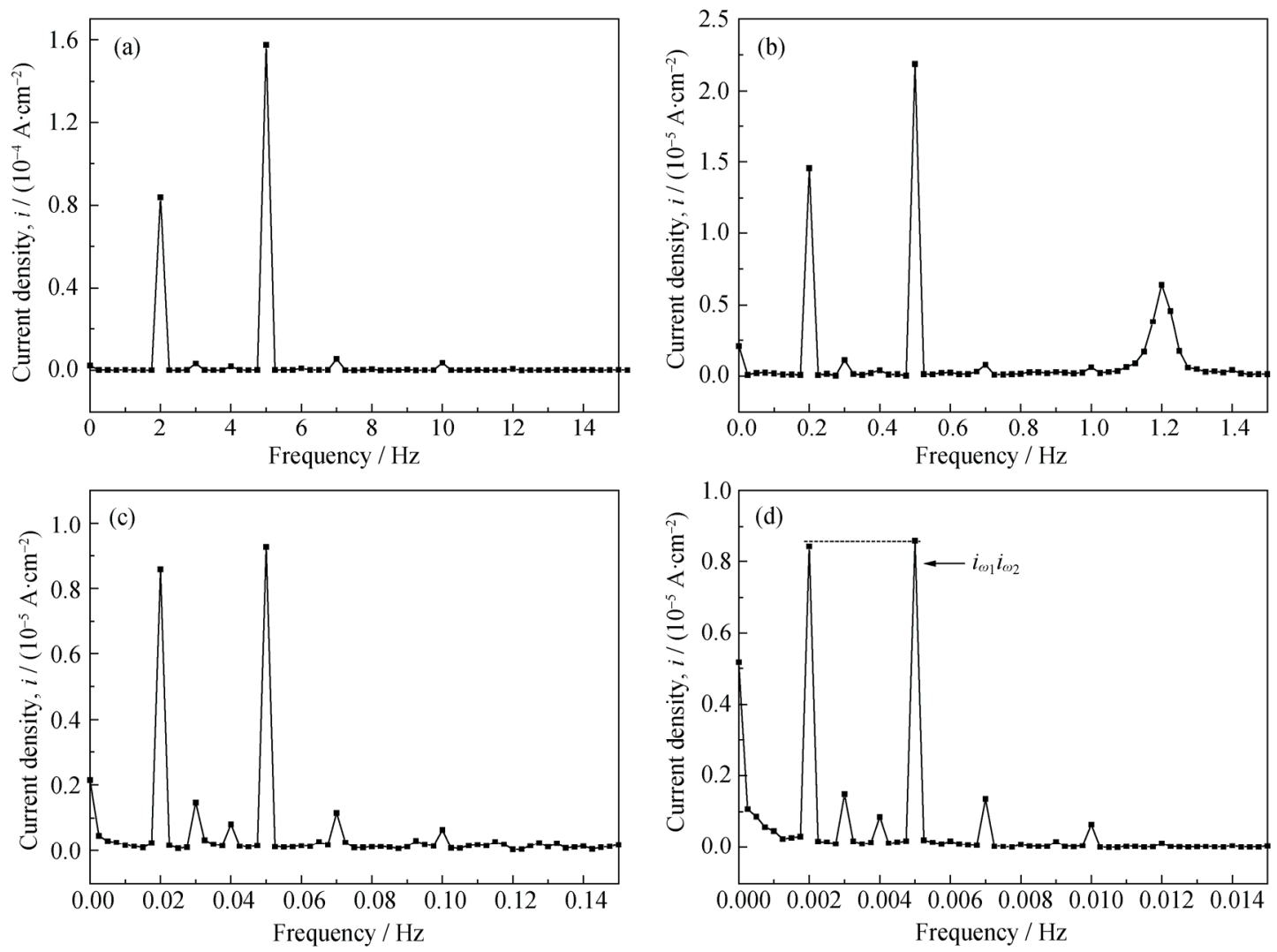

Fig. 10. Frequency-domain current response spectra obtained at different base frequencies for Q345B immersed in 3.5wt $\% \mathrm{NaCl}$ solution: (a) $1.0 \mathrm{~Hz}$; (b) $0.1 \mathrm{~Hz}$; (c) $0.01 \mathrm{~Hz}$; (d) $0.001 \mathrm{~Hz}$.

Second, a large difference also exists in the data analysis methods associated with the EFM and EIS techniques. With an $\mathrm{AC}$ voltage signal $E(t)$ disturbance, the current response should be described by the following equation:

$$
i=i_{\mathrm{f}}+i_{\mathrm{c}}=i_{\text {corr }}\left[\exp \left(\frac{2.3 \Delta E}{b_{\mathrm{a}}}\right)-\exp \left(\frac{-2.3 \Delta E}{b_{\mathrm{c}}}\right)\right]+C \frac{\mathrm{d} E(t)}{\mathrm{d} t}
$$

where $i_{\mathrm{f}}$ is the Faradic current component and $i_{\mathrm{c}}$ is the capacitive current component (i.e., the non-Faradic current component). In the case of EFM, the non-Faradic current components were neglected in the mathematical treatment. Therefore, lower frequencies resulted in better measurement precision because low frequencies avoid the capacitive current component. By contrast, both the Faradic and non-Faradic current components are rigorously taken into account in the EIS mathematical treatment, providing more information on corrosion kinetics but sometimes causing difficulties in data analysis. Consequently, the differences in both the disturbance signal and the mathematical treatment resulted in different results for the EIS (Figs. 5 and 6) and the EFM (Figs. 9 and 10) methods in the low-frequency region.

\subsection{Comprehensive comparison}

All of the results obtained using the aforementioned methods are listed in Table 3 for comparison. The $R_{\mathrm{p}}$ evaluated from TC4 and EFM $(0.001 \mathrm{~Hz})$ are 1577 and $1669 \Omega \cdot \mathrm{cm}^{2}$, respectively, which are roughly consistent with the values obtained by LPR and EIS. The $b_{\text {a }}$ determined by Tafel-curve linear fitting, four-parameter fitting, and EFM $(0.001 \mathrm{~Hz})$ are in agreement with each other, whereas the $b_{\mathrm{c}}$ estimated by Tafel-curve three-parameter fitting, four-parameter fitting, and EFM $(0.001 \mathrm{~Hz})$ are somewhat scattered. However, the $B$ values acquired by Tafel-curve four-parameter fitting and the EFM method $(0.001 \mathrm{~Hz})$ are 19.4 and 21.2, respectively, and are therefore similar. Both the $i_{\text {corr }}$ values evaluated by Tafel-curve four-parameter fitting and the EFM method $(0.001 \mathrm{~Hz})$ are in accordance with that determined by coupon tests. However, the $i_{\text {corr }}$ value of $18.8 \mu \mathrm{A} \cdot \mathrm{cm}^{-2}$ estimated by extrapolating the linear fitting of the anodic polarization curve was larger. These phenomena imply that the natural corrosion situation was destroyed under strong polarization. For the examined corrosion system, the curve in the cathodic branch and in the relatively weak polarization region (for an instance, -150 to $+30 \mathrm{mV}$ vs. $\left.E_{\text {corr }}\right)$ is more reliable for evaluating the situation at OCP. 
Table 3. Comparison of the corrosion kinetic parameters of Q345B/3.5wt\% NaCl estimated through different methods in this work

\begin{tabular}{|c|c|c|c|c|c|c|}
\hline Comparison & $\begin{array}{c}R_{\mathrm{p}} / \\
\left(\Omega \cdot \mathrm{cm}^{2}\right)\end{array}$ & $\begin{array}{c}b_{\mathrm{a}} / \\
\left(\mathrm{mV} \cdot \mathrm{dec}^{-1}\right)\end{array}$ & $\begin{array}{c}b_{\mathrm{c}} / \\
\left(\mathrm{mV} \cdot \mathrm{dec}^{-1}\right)\end{array}$ & $\begin{array}{c}B / \\
\left(\mathrm{mV} \cdot \mathrm{dec}^{-1}\right) \\
\end{array}$ & $\begin{array}{c}i_{\text {corr }} / \\
\left(\mu \mathrm{A} \cdot \mathrm{cm}^{-2}\right)\end{array}$ & $\begin{array}{c}\text { Duration of } \\
\text { measurement }\end{array}$ \\
\hline $\mathrm{LPR}(0.3-1.0 \mathrm{mV} / \mathrm{s})$ & 1593 & - & - & - & - & $\sim 1 \mathrm{~min}$ \\
\hline EIS (multi-frequency: $10^{5}-0.01 \mathrm{~Hz}$ ) & 1639 & - & - & - & - & $20 \mathrm{~min}$ \\
\hline Tafel-curve linear fitting & - & 81.9 & - & - & 18.8 & $\sim 5 \mathrm{~min}$ \\
\hline Tafel-curve three-parameter fitting & - & - & 68.5 & - & 5.0 & $\sim 5 \mathrm{~min}$ \\
\hline Tafel-curve four-parameter fitting & $1577^{*}$ & 78.4 & 103.0 & 19.4 & 12.3 & $\sim 5 \mathrm{~min}$ \\
\hline $\operatorname{EFM}(0.001 \mathrm{~Hz})$ & $1669^{*}$ & 64.9 & 195.9 & 21.2 & 12.7 & $\sim 84 \min$ \\
\hline Coupon test (immersion time: $12 \mathrm{~h}$ ) & - & - & - & - & 12.5 & $12 \mathrm{~h}$ \\
\hline
\end{tabular}

Note: ${ }^{*}$ The values of 1577 and $1669 \Omega \cdot \mathrm{cm}^{2}$ were calculated using the equation $R_{\mathrm{p}}=\frac{B}{i_{\text {corr }}}$.

The durations of all of the aforementioned measurements are included in Table 3 for reference. The coupon test method is the most time-consuming, and the EFM method with a base frequency of $0.001 \mathrm{~Hz}$ is the second-most time-consuming. LPR is the least time-consuming method; however, it provides little information other than a value for $R_{\mathrm{p}}$. Tafel curves are quite informative, but the test causes large disturbance to the metal.

The results of the present study further suggest that the flexible and collaborative application of multiple techniques could provide a more reliable and complete profile of the target corrosion system. Taking the methods that involve less disturbance to the examined system as examples, EIS measurements provide information about the mechanism of electrode kinetics, which can ensure the adaptability of other detection techniques and data analysis approaches. For an activation-controlled system, the EFM method can be conducted subsequently to estimate the kinetic parameters. Otherwise, if the corrosion is influenced (controlled or mix-controlled) by a mass transfer process (e.g., diffusion of dissolved $\mathrm{O}_{2}$ ), then Tafel multiparameter fitting might be a better choice for determining the corrosion kinetics; in this case, a combined application of linear fitting, three-parameter fitting, and four-parameter fitting is highly recommended.

Notably, in this paper, a contradiction was encountered between the TC4 method and the EFM method during the fitting process. Whereas the former considers the mass transfer process (e.g., the diffusion of dissolved $\mathrm{O}_{2}$ ), the latter does not. Although a diffusion-controlled phenomenon appeared in the strong polarization region of the Tafel curve (Fig. 7), the occurrence of this phenomenon cannot be taken as a full indication for diffusion control at the open-circuit condition. Instead, the EIS test with $\pm 5 \mathrm{mV}$ vs. $E_{\text {corr }}$ excitation can better reflect the kinetic process of corrosion under natural conditions. To demonstrate the change of the control process over time, the results of a series of EIS experiments conducted at different immersion times are shown in Fig. 11. No sign of diffusion control is evident at the early immersion stage; the diffusion-control phenomenon appears after more than $50 \mathrm{~h}$.

\section{Conclusions}

(1) The advantages and disadvantages of several electrochemical methods for Q345B/3.5 wt $\% \mathrm{NaCl}$ solution corrosion detection were comparatively investigated in this work. The coupon test is the most conventional approach to evaluating the corrosion rate of such metals. It can provide $e x$ situ information about the average corrosion rate and the corrosion morphology to aid in identification of the type of corrosion. LPR and EIS can be used to estimate the polarization resistance; however, they can only be used to estimate the corrosion rate when the Tafel constants are already known. Tafel-curve multiparameter fitting can accurately determine numerous electrochemical kinetic parameters through comprehensive use of linear fitting, three-parameter fitting, and four-parameter fitting. However, the potential polarization supplied for the Tafel test is relatively large, which may destroy the equilibrium state of the specimen surface. In the case of EFM measurements, a comparison of the values of $\mathrm{CF}(2)$ and $\mathrm{CF}(3)$ suggested that adopting 0.001 $\mathrm{Hz}$ as the base frequency is the best choice.

(2) A comparison shows that, for the examined corrosion system, the in situ kinetic parameters obtained by EFM $(0.001 \mathrm{~Hz})$ and Tafel-curve four-parameter fitting are more reliable than the other electrochemical methods used in this work. Although the EFM method with a base frequency of $0.001 \mathrm{~Hz}$ is somewhat time-consuming, it can accurately determine numerous electrochemical kinetic parameters while only weakly disturbing the system. By contrast, EIS cannot directly identify the corrosion rate but is very useful for distinguishing the kinetic model of the corrosion system. 

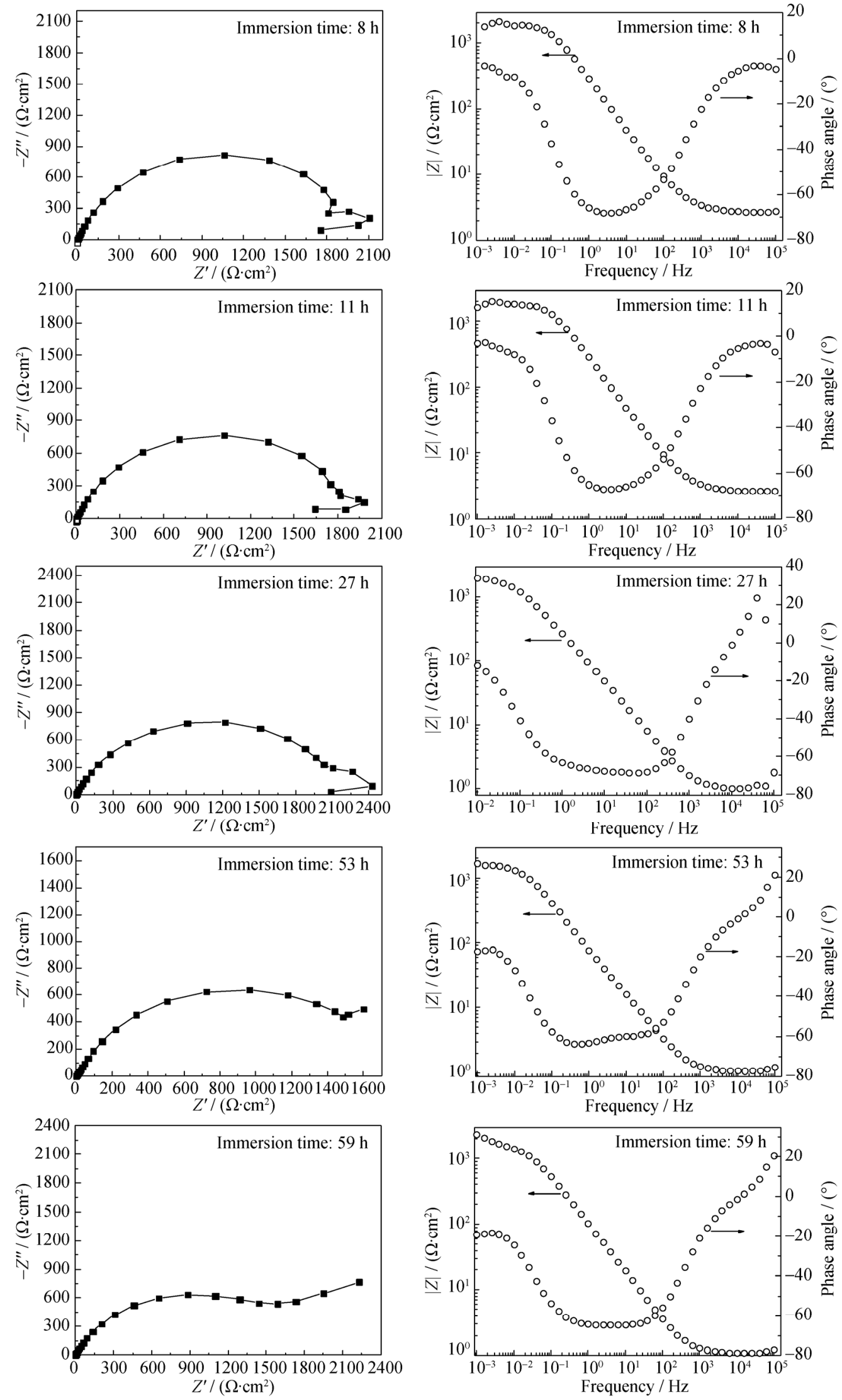

Fig. 11. A series of EIS experiments for Q345B immersed in 3.5wt\% NaCl solution for different immersion times. Left: Nyquist plots; right: Bode plots. 
Therefore, on the basis of the present results, the collaborative application of EIS and EFM/TC4 is the approach recommended for in situ monitoring of the corrosion of Q345B in seawater in its early stage.

\section{Acknowledgements}

This work is supported by the Programme of Introducing Talents of Discipline to Universities (No. B12012). The authors would like to thank K. Nakagawa from Ishikawajima-Harima Heavy Industries Co., Ltd. and J.S. Pan from KTH Royal Institute of Technology (KTH, Swedish: Kungliga Tekniska Högskolan) for fruitful discussion.

Open Access This article is distributed under the terms of the Creative Commons Attribution 4.0 International License (http://creativecommons.org/licenses/by/4.0/), which permits unrestricted use, distribution, and reproduction in any medium, provided you give appropriate credit to the original author(s) and the source, provide a link to the Creative Commons license, and indicate if changes were made.

\section{References}

[1] G.S. Frankel, Electrochemical techniques in corrosion: status, limitations, and needs, J. ASTM Int., 5(2008), No. 2, p. 1.

[2] G.L. Edgemon, Electrochemical noise based corrosion monitoring at the Hanford site: third generation system development, design, and data, [in] Corrosion 2001, NACE International, Houston, 2001, art. No. NACE-01282.

[3] B. Kursten, F. Druyts, L. Areias, Y. van Ingelgem, D. De Wilde, G. Nieubourg, G.S. Duffó, and C. Bataillon, Preliminary results of corrosion monitoring studies of carbon steel overpack exposed to supercontainer concrete buffer, Corros. Eng. Sci. Technol., 49(2014), No. 6, p. 485.

[4] S. Girija and U. Kamachi Mudali, Electrochemical noise resistance evaluation of 304L SS in nitric acid and simulated nuclear high level waste, Corros. Eng. Sci. Technol., 49(2014), No. 5, p. 335.

[5] M. Barbalat, D. Caron, L. Lanarde, M. Meyer, S. Fontaine, F. Castillon, J. Vittonato, and P. Refait, Estimation of residual corrosion rates of steel under cathodic protection in soils via voltammetry, Corros. Sci., 73(2013), p. 222.

[6] M. Barbalat, L. Lanarde, D. Caron, M. Meyer, J. Vittonato, F. Castillon, S. Fontaine, and P. Refait, Electrochemical study of the corrosion rate of carbon steel in soil: Evolution with time and determination of residual corrosion rates under cathodic protection, Corros. Sci., 55(2012), p. 246.

[7] F.J. Ansuini and J.R. Dimond, Field tests on an advanced cathodic protection coupon, [in] Corrosion 2005, NACE International, Houston, 2005, art. No. NACE-05039.

[8] S.Y. Li, Y.G. Kim, S. Jung, H.S. Song, and S.M. Lee, Application of steel thin film electrical resistance sensor for in situ corrosion monitoring, Sens. Actuators B, 120(2007), No. 2, p. 368.
[9] F. Varela, M.Y.J. Tan, and M. Forsyth, An overview of major methods for inspecting and monitoring external corrosion of on-shore transportation pipelines, Corros. Eng. Sci. Technol., 50(2015), No. 3, p. 226.

[10] P.R. Roberge, M.A.A. Tullmin, L. Grenier, and C. Ringas, Corrosion surveillance for aircraft, Mater. Perform., 35(1996), No. 12 , p. 50.

[11] F. Pruckner, J. Theiner, J. Eri, and G.E. Nauer, In-situ monitoring of the efficiency of the cathodic protection of reinforced concrete by electrochemical impedance spectroscopy, Electrochim. Acta, 41(1996), No. 7-8, p. 1233.

[12] A. Del Valle-Moreno, J. Genescá-Llongueras, A.A. Torres-Acosta, and M. Martínez, EIS monitoring of cathodic protection of steel reinforced concrete enhanced by humectants, ECS Trans., 20(2009), No. 1, p. 489.

[13] C. Andrade, J. Sanchez, J. Fullea, N. Rebolledo, and F. Tavares, On-site corrosion rate measurements: 3D simulation and representative values, Mater. Corros., 63(2012), No. 12, p. 1154.

[14] V. Saraswathy and S.P. Karthick, Effect of ecofriendly sealing coat against corrosion protection of steel rebars in concrete, Corros. Eng. Sci. Technol., 49(2014), No. 5, p. 327.

[15] M. Wasim and R.R. Hussain, Comparative study on induced macrocell corrosion phenomenon in repaired ordinary reinforced and self-compacting concrete structures, Corros. Eng. Sci. Technol., 48(2013), No. 5, p. 370.

[16] T. Prosek, N. Le Bozec, and D. Thierry, Application of automated corrosion sensors for monitoring the rate of corrosion during accelerated corrosion tests, Mater. Corros., 65(2014), No. 5, p. 448.

[17] M. Kouril, T. Prosek, B. Scheffel, and F. Dubois, High sensitivity electrical resistance sensors for indoor corrosion monitoring, Corros. Eng. Sci. Technol., 48(2013), No. 4, p. 282.

[18] A. Dravnieks and H.A. Cataldi, Industrial applications of a method for measuring small amounts of corrosion without removal of corrosion products, Corrosion, 10(1954), No. 7, p. 224.

[19] A.J. Freedman, E.S. Troscinski, and A. Dravnieks, An electrical resistance method of corrosion monitoring in refinery equipment, Corrosion, 14(1958), No. 4, p. 29.

[20] L.T. Yang, Techniques for Corrosion Monitoring, Woodhead Publishing Ltd., Cambridge, 2008, p. 277.

[21] D. Thierry, A. Taher, and C. Leygraf, Corrosion monitoring techniques applied to cooling water and district heating systems, [in] Corrosion 87, NACE International, 1987, art. No. NACE-87463.

[22] K.B. Oldham and F. Mansfeld, Corrosion rates from polarization curves: A new method, Corros. Sci., 13(1973), No. 10, p. 813.

[23] F. Mansfeld, Simultaneous determination of instantaneous corrosion rates and Tafel slopes from polarization resistance measurements, J. Electrochem. Soc., 120(1973), No. 4, p. 515.

[24] F. Mansfeld, Tafel slopes and corrosion rates from polarization resistance measurements, Corrosion, 29(1973), No. 10, p. 397.

[25] F. Mansfeld and M. Kendig, Technical note: concerning the choice of scan rate in polarization measurements, Corrosion, 37(1981), No. 9, p. 545.

[26] C.N. Cao, Estimation of electrochemical kinetic parameters of corrosion processes by weak polarization curve fitting, $J$. Chin. Soc. Corros. Prot., 5(1985), No. 3, p. 155. 
[27] Y.T. Zhao and X.P. Guo, Determination of electrochemical kinetic parameters in a mixture controlled corrosion system, Acta Phys. Chim. Sinica, 22(2006), No. 10, p. 1281.

[28] Y. Sun, J.E. Remias, J.K. Neathery, and K. Liu, Electrochemical study of corrosion behaviour of carbon steel A106 and stainless steel 304 in aqueous monoethanolamine, Corros. Eng. Sci. Technol., 46(2011), No. 6, p. 724.

[29] G.B. Chen, H.Y. Yang, and H.J. Li, In situ characterization of natural pyrite bioleaching using electrochemical noise technique, Int. J. Miner. Metall. Mater., 23(2016), No. 2, p. 117.

[30] Y.L. Huang, H. Shih, H.C. Huang, J. Daugherty, S. Wu, S. Ramanathan, C. Chang, and F. Mansfeld, Evaluation of the corrosion resistance of anodized aluminum 6061 using electrochemical impedance spectroscopy (EIS), Corros. Sci., 50(2008), No. 12, p. 3569.

[31] D. Mareci, I. Rusu, R. Chelariu, G. Bolat, C. Munteanu, D. Sutiman, and R.M. Souto, Application of dynamic electrochemical impedance spectroscopy to the evaluation of the corrosion resistance of a historic bronze object in artificial acid rainwater, Eur. J. Sci. Technol., 9(2013), No. 6, p. 189.

[32] L.N. Xu, J.Y. Zhu, M.X. Lu, L. Zhang, and W. Chang, Electrochemical impedance spectroscopy study on the corrosion of the weld zone of $3 \mathrm{Cr}$ steel welded joints in $\mathrm{CO}_{2}$ environments, Int. J. Miner. Metall. Mater., 22(2015), No. 5, p. 500.

[33] O. Schneider and R.G. Kelly, Localised coating failure of epoxy coated aluminium alloy $2024-\mathrm{T} 3$ in $0.5 \mathrm{M} \mathrm{NaCl}$ solutions: comparison of conventional electrochemical techniques and microelectrochemical methods, Corros. Eng. Sci. Technol., 38(2003), No. 2, p. 119.

[34] S. Sathiyanarayanan and K. Balakrishnan, Critique of harmonic analysis for corrosion rate measurements, $\mathrm{Br}$. Corros. J., 29(1994), No. 2, p. 152.

[35] K. Darowicki and J. Majewska, Harmonic analysis of electrochemical and corrosion systems - a review, Corros. Rev., 17(1999), No. 5-6, p. 383.

[36] J. Jankowski, Harmonic synthesis: A novel electrochemical method for corrosion rate monitoring, J. Electrochem. Soc., 150(2003), No. 4, p. B181.

[37] C. Andrade and C. Alonso, Corrosion rate monitoring in the laboratory and on-site, Constr. Build. Mater., 10(1996), No. 5, p. 315.

[38] Y. Zou, J. Wang, and Y.Y. Zheng, Electrochemical tech- niques for determining corrosion rate of rusted steel in seawater, Corros. Sci., 53(2011), No. 1, p. 208.

[39] M. Stern and A.L. Geary, Electrochemical polarization I. A theoretical analysis of the shape of polarization curves, $J$. Electrochem. Soc., 104(1957), No. 1, p. 56.

[40] D. Li, Electrochemistry Theory, Beihang University Press, Beijing, 1999, p. 308.

[41] R.W. Bosch, J. Hubrecht, W.F. Bogaerts, and B.C. Syrett, Electrochemical frequency modulation: A new electrochemical technique for online corrosion monitoring, Corrosion, 57(2001), No. 1, p. 60.

[42] E. Kuș and F. Mansfeld, An evaluation of the electrochemical frequency modulation (EFM) technique, Corros. Sci., 48(2006), No. 4, p. 965.

[43] L. Han and S.Z. Song, Using electrochemical frequency modulation technique to detect corrosion of carbon steel in seawater, J. Chem. Ind. Eng., 59(2008), No. 4, p. 977.

[44] J.A. González, A. Molina, M.L. Escudero, and C. Andrade, Errors in the electrochemical evaluation of very small corrosion rates-I. Polarization resistance method applied to corrosion of steel in concrete, Corros. Sci., 25(1985), No. 10, p. 917.

[45] J.A. González, A. Molina, M.L. Escudero, and C. Andrade, Errors in the electrochemical evaluation of very small corrosion rates-II. Other electrochemical techniques applied to corrosion of steel in concrete, Corros. Sci., 25(1985), No. 7, p. 519.

[46] R.E. Melchers and R. Jeffrey, Early corrosion of mild steel in seawater, Corros. Sci., 47(2005), No. 7, p. 1678.

[47] B.M. Wei, Metal Corrosion Theory and Application, Chemical Industry Press, Beijing, 1984, p. 96.

[48] Y.S. Wu, The Research Methods of Metal Corrosion, Metallurgical Industry Press, Beijing, 1993, p. 71.

[49] S.L. Gojković, S.K. Zečević, M.D. Obradović, and D.M. Dražlć, Oxygen reduction on a duplex stainless steel, Corros. Sci., 40(1998), No. 6, p. 849.

[50] N. Le Bozec, C. Compère, M. L'Her, A. Laouenan, D. Costa, and P. Marcus, Influence of stainless steel surface treatment on the oxygen reduction reaction in seawater, Corros. Sci., 43(2001), No. 4, p. 765.

[51] A. Davydov, K.V. Rybalka, L.A. Beketaeva, G.R. Engelhardt, P. Jayaweera, and D.D. Macdonald, The kinetics of hydrogen evolution and oxygen reduction on Alloy 22, Corros. Sci., 47(2005), No. 1, p. 195. 